\title{
Organisational Conflict: A Review of the Literature
}

\author{
Taher Mohamed
}

Ph.D. Student, University of Kastamonu, Management College, Business Administration Department, Turkey

\begin{abstract}
Organizational conflict refers to the condition of misunderstanding or disagreement that is caused by the perceived or actual opposition in the needs, interests and values among people who work together. Organizational conflict may also be termed as workplace conflict. The conflicts occur during situations where there is an interaction between two or more members of an organization involving contradictory opinions. Organizational conflicts are influenced by a variety of factors like the lack of clarity in the responsibility of the team members, the interpersonal relationship that is shared by the members of the organization. The scarcity of the needed resources may lead to the rise of conflict between the members of the organization. This study attempts to look into the two theories of the organizational conflict. These theories are the organizational conflict theory and the conflict management theory.
\end{abstract}

Keywords: Organizational conflict, Organizational Conflict theory, Change Management Theory

\section{Introduction}

Organizational conflict refers to the condition of misunderstanding or disagreement that is caused by the perceived or actual opposition in the needs, interests and values among people who work together. Organizational conflict may also be termed as workplace conflict. The conflicts occur during situations where there is an interaction between two or more members of an organization involving contradictory opinions. These opinions may be brought forward concerning any particular decision or task that has taken place within the organization. Organizational conflict, in simpler terms, implies to the outcomes of the human interaction that commences with the declaration of a member of the organization that his values, attitudes or goals are not compatible with the attitude, values or goals that have been set by the organization and needs to be followed by the members of the organization (Siira, 2012). The incompatibility of the opinions may arise between two members of the organization working in the same group, between two groups of members in the organization or within a person who is working member of an organization. There are several types of conflicts that may arise within an organization. The various types of conflicts are the task conflicts, process conflicts and the relationship conflicts.

Organizational conflicts are influenced by a variety of factors like the lack of clarity in the responsibility of the team members, the interpersonal relationship that is shared by the members of the organization. The scarcity of the needed resources may lead to the rise of conflict between the members of the organization. The disagreement of the members on the fields of interest may also lead to the conflicts and altercations within the workplace. The main causes of the organizational conflict are the disruption of the communication, the lack of accountability on the part of the members (Marion \& Gonzales, 2013). The misunderstanding on the part of the employees may also lead to the conflicts within the organization. Organizational conflict may also arise from the conditions where the targets that are set by the superiors are not met by the employees who work under their supervision (Bhat et al, 2013). The following report deals with the theories of the conflict within the organization. The report aims to look into the causes behind the conflict within the organizations, the different types of the conflicts and the factors that influence the incidents of organizational conflict. The report, on the concluding note, attempts to look into some ways that may be helpful in the management of the conflicts that arise among the members of the organization.

\section{Organizational Conflict}

A condition at the workplace that includes the misunderstanding or miscommunication among the employees of the organization due to the actual or the perceived contradiction of the needs, interests and values may be referred to as the organizational conflict. There may be many forms of conflict that takes place in the organizations. The clash between the formal power and authority and the sufferers or the affected groups and individuals. There may be disputes over the issues of division of revenues, the ways in which the task at hand might be accomplished. The conflicts may also arise over the working hours and techniques of the employees. There may occur some jurisdictional disagreements among the departments, individuals and among the management and the employee unions that exist within the concern (Katzenbach \& Smith, 2015). The subtle forms of the conflicts refer to the jealousies, rivalries, personality clashes, struggles for the favor and power and the role divisions. The individual employees may respond differently to the various demanding situations that arise in the process of working.

\section{Influencing Factors}

There are various factors that may influence the conflicts that may arise within an organization.

- Lack of clarity of responsibility - Conflict arises in a situation where the responsibility of the employees is not clearly mentioned. In order to avoid these situations, the responsibilities and roles of each member must be stated clearly in advance in order to avoid such discrepancies. These discrepancies lead to conflicts within the concern in future (Prause \& Mujtaba, 2015).

- Interpersonal relationships - The issues of interpersonal relationship among the employees may lead to the conflicts that arise within an organization. The difference in the personalities of the employees may at times prove 


\section{International Journal of Science and Research (IJSR) \\ ISSN (Online): 2319-7064}

Index Copernicus Value (2016): 79.57 | Impact Factor (2015): 6.391

helpful towards the solving of the conflicts that arise in the workplace.

- Scarce resources - Inadequate resources often lead to the developments of issues at the workplace, which in the due course of time may lead to the serious conflicts. Members of an organization often compete with each other on the availability of the resources like the materials required, the amount of money that needs to be spent, and the time required for the completion of the task at hand.

- Interest issues - The disorientation between the organizational goals and the goals of the concerned individual may lead to a conflict. The concerned individual may fight for his own personal goals, which in turn leads to the hindrances in the overall success of the project that the team is working on.

Apart from the above-discussed factors, there are more factors that influence the conflicts that take place within an organization. These factors include both the individual and the factors dealing with the activities that involve a number of individuals. The conflict that arises when a managerial staff breaches or defies the norms of the given organization may be termed to be an inter-individual conflict within the organization (Abiodun, 2014). The individual factors that result in conflicts within the organization are the beliefs, personality orientation, attitudes and other such human frailties that exist within the individuals working in an organization (Moore, 2014).

\section{Types of Conflict Arising in the Organizations}

There are several types of conflicts that may arise within an organization. The primary types of conflict that the organizations generally face are enlisted below.

- Relationship conflict - This type of conflict may arise from the interpersonal tension that exists between the employees of the concerned organization. These conflicts are concerned intrinsically with the persons. They do not concern the project or the assignment at hand.

- Task conflict - These conflicts arise from the discordance that exists among the employees regarding the nature of the particular job at hand. These conflicts generally involve the members of the organization and the management of the concerned organization (de Wit, Jehn \& Scheepers, 2013)

- Conflict of process - This conflict arises among the members of the same team. These conflicts arise from the differences in the opinions of the members regarding the ways in which the task should be completed. In order to avoid these conflicts, the team members must discuss the work strategy before commencing the job. The investor of the Target Corporation William Ackman had raised an issue with the management of the retailer chain. The conflict in this case was raised in the field of the change that Ackman felt was necessary in the business strategy of the organization.

Organizational conflict may also refer to the personal conflicts, the intergroup conflicts and the intragroup conflicts. The personal conflicts refer to the ones that exist between two members of the organization. These conflicts arise due to the mutual dislike that exists between the members. The intergroup conflicts, as the name suggests, refer to the conflicts that may arise due to the differences in the opinions between two groups of members that wok within the same organization. The intragroup conflicts refer to the conflicts between the members of the same work group. These differences arise from the lack of resources, liberty of the employees of the team and other such internal factors (Babatunde, 2013).

\section{Causes of the Conflict}

There are many causes that result in the organizational conflicts to arise. These causes are enlisted below.

- Expectations of the managerial staff - The management expects all the employees to meet the targets that are set by their superiors. The discrepancies in the understanding of the task at hand or the inability on the part of the employee to achieve the set targets results in the conflicts that arise in the concerned workplace.

- Disruption in the communication - One of the major causes of the conflicts that arise in the workplace is the disruption that occurs within the members working in the same organization. These conflicts may arise in situations where a member may be in need for some information from another colleague who does not reply in a proper manner or does not provide with the needed information (Halevy et al, 2014).

- Misunderstanding - This is the most common cause of the arousal of conflict within an organization. These conditions may arise when one member of the organization misinterprets the information that has been conveyed to him. This may lead to the creation of a number of conflicts that may prove disturbing towards the overall growth of the organization (Chen et al, 2012).

- Accountability lack - There may be situations in the organization whereby the responsibilities of the member are not clearly stated. In any dispute and mistake conditions that arise, no member of the concerned team or group is ready to take responsibility. This may lead to conflicts between the employees of the organization.

In order to resolve the conflicts within the organization, the factors that cause the conflicts must be clearly addressed. These conflicts if unresolved may pose a hindrance to the effectiveness, efficiency and the productivity of the members employed within the organization. This may hamper the overall growth of the company thereby reducing the success of the company on a larger scale.

\section{Ways to manage the conflicts}

The arousal of conflicts within an organization is an inevitable condition. The concerned company must devise various ways to deal with those conflicts; thereby helping the organization to bring about a rise in the productivity. The conflicts within an organization must be handled positively in order to avoid the recurrence of the same problem. The company should have a proper procedure to address the grievances of the all the members of the concerned organization. The organizational managers should concentrate more on the causes of the conflict rather than the effects of the same in order to assess the conflicts in a proper 


\section{International Journal of Science and Research (IJSR) \\ ISSN (Online): 2319-7064}

Index Copernicus Value (2016): 79.57 | Impact Factor (2015): 6.391

manner. The parties involved in the conflict must have an equal say while the conflict is being addressed. The parties must not be judged based on their terms, position in the company or the political influence that they may have over the other members of the organization. The active participation of all the members involved in the conflict should be demanded in order to counter the situation that may result from the situation of the conflict (Graham, 2014). IBM, for example, is benefitted from the diversity that it has in terms of the employees of the organization. The employees of the organization participate actively in order to solve the issues that may arise within the organization.

\section{Theories of organizational conflicts}

There may be many theories that explain the issues of the organizational conflicts. Some of these theories are the "Organizational Conflict Theory", the "Conflict Management Theory"

\section{Organizational Conflict Theory}

The conflict at the workplace is inevitable. The organizational conflict theory states that there are a varied number of conflicts that arise within an organization. Interpersonal conflicts being the most common type of workplace conflict, there are some other areas of conflict as well. These include the inter-departmental conflicts, the struggle for power among the senior managerial members, the inter-organizational conflicts. According to some of the theorists, these conflicts must be resolved to allow the smooth progress of the organization, while others opine that the conflicts at the workplace helps to drive the company towards success (Nain, 2017).

\section{Interpersonal Conflicts}

The interpersonal conflicts suggest that the members of a given organization may not always mix well with each other. The members of the organization may not wish to socialize among themselves while they are at their workplace. In case of work, if they are to work together, conflict may be seen between them (Mikkelsen \& Clegg, 2017).

\section{Role Conflict}

The other type of conflict includes role conflicts. These conflicts are not due to their individual personalities or values but results from situations relating to their roles and responsibilities. These kinds of conflicts are witnessed in instances wherein a nurse manager ordering a nurse not to perform tests on a patient as his insurance does not cover those tests, whereas the nurse is bound by her ethical boundaries to save the patient. These conflicts are usually resolved by the higher authorities.

\section{Maturity and Immaturity Theory}

The maturity theory holds the view that people should want to develop and mature in their professional lives in the similar way as they do in their personal lives. This is in conflict with the Immaturity theory, which is witnessed in many hierarchy-based industries where the tasks are segregated in micro-specialties. This limits the growth area of the employees thus providing dissatisfaction of the workers as whole. This leads to conflict between the people following the two theories. From an individual point of view the workers might develop resentment and might begin forming unions, and in extreme cases revolt. Industries promoting an intense level of specialization and less flexibility may usually witness frequent conflicts resulting from the maturity-immaturity theory (Lumineau, Eckerd \& Handley, 2015).

\section{Intergroup conflict}

This is a common occurrence at workplace scenarios where one group of workers might find themselves at a face-to-face junction with another group. This happens when, in order to perform one of their tasks, one group creates or rather obstructs the workflow of another group. This might be very damaging to the organization body as a whole if escalated. Thus, such a problem needs to be resolved as soon as it arises (Kerzner, 2013).

\section{Causes}

There are several plausible causes of organizational conflicts. Mostly they involve factors such as mismatch of opinions between members of the same team or maybe a difference of understanding between authorities at workplace (Franks et al, 2014). A few main reasons for conflicts in organizational environment are discussed below.

\section{Communication Issues}

One of the most significant issues of organizational conflicts include poor communication or miscommunication. Different communication patterns often lead to misinterpretation of various topics, which lead to a false impact on the brain regarding the person talking on the topic. This results in a conflicting attitude on the discussion itself. A simple instance like a manager reassigning a worker's task to his/her colleague, but failing to mention it to the concerned worker, or communicating his intentions to the worker before assigning the task, might lead to the employee harboring negative perception about the manager. Repetitive occurrences of this nature in the future might lead to the employee's poor organizational conduct as a whole or towards the manager and might lead to serious organizational conflicts. Thus, it can be observed how miscommunication or absence of proper communication leads to conflict within an organization. Hence, poor communication not only gives rise to conflicts in the workplace itself but also negatively affects productivity of the entire working group (Odle-Dusseau, Britt \& GreeneShortridge, 2012).

\section{Organizational Structure}

The structure wherein an organization is formed plays a very determining role in the conflict area. A simple example can be observed in the fact that in case of a matrix-structured company, decisional conflicts are almost built-in, as it is specified in the structure itself that an employee should report to two bosses (Gelfand et al, 2012). This type of a structure will almost always lead to confusion as the company is segmented into smaller parts, always having two opinions on one issue.

\section{Authority Responsibility Relationship}

The design of authority in the organizational structure determines the chances of arising of a conflict. An illdefined authority-responsibility relationship will definitely lead to a conflict. The lack of consistency in work is observed when such authority-responsibility relationships

\section{Volume 6 Issue 12, December 2017}




\section{International Journal of Science and Research (IJSR) \\ ISSN (Online): 2319-7064}

Index Copernicus Value (2016): 79.57 | Impact Factor (2015): 6.391

are not properly or rather clearly defined. Communication problems creep in and crack open wedges of conflict. Intergroup conflicts are usual results of such weak organizational structures (Sonnentag, Unger \& Nägel, 2013).

\section{Contradicting Personalities}

This encircles one of the most common reasons for conflict in office scenarios. Differences in personality in the workplace are as common and expected as sand on a seashore. Employees come to work from different ethnic backgrounds, having had different experiences and harbor a different and individualistic mindset, thus forming a unique character of each to understand. In the case when one worker fails to understand the other in certain areas or maybe in areas relating to the area of the work assigned to them, conflicts take place (Deyoe \& Fox, 2012). A proper instance might include having a straightforward-minded employee who believes in speaking the truth or what he feels directly, without considering the effects of it. This straightforward persona might affect or insult the other workers surrounding if it is such a topic. Sometimes the person with the straightforward attitude might feel offended as well in case the other workers do not behave in that manner with him and keep stuff away from him.

\section{Frustration and Stress}

Conflict arises in situations where the parties involved are too stressed out or frustrated with their own work. Stressed out people are more likely to start a quarrel with a properly functioning co-worker. This shall in turn reduce productivity on the overall front. Causes of such stress can be as simple as unwanted noise, lack of privacy, untidy workplace, or very serious such as threats of violence, harassment, extreme negative criticism (Riaz \& Junaid, 2012).

\section{Competition centering Resources}

Resources like equipment, money or time are usually limited and scarce. It is a very natural phenomenon that competition among workers for such resources is a frequent source of conflict. Cutting-edge gadgets and accessories like laptops and iPhones might be allocated to a certain rank of employees whereas others may be deprived of it. Some employees might hold the view that those technical devices are crucial for their productivity and might revolt in extreme cases. This leads to severe competition at times. Such unhealthy competition gives rise to an unethical environment in the office itself, thus lowering the workplace morale as a whole. This in turn demotes teamwork and encourages individualism (Katz \& Flynn, 2013).

\section{Dependency Issues}

One of the significant causes of conflict involves task interdependence. The cases where completion of one's task involves other co-workers to perform equally their tasks, conflicts regarding efficiency or sincerity of the co-workers, are usually seen. Group projects, like creating an advertisement for an item usually suffers from such conflicts, as one is dependent on the creative team for the main design and layout, the photographer for the visual effects and so on and so forth. Lack of efficiency in one sector holds the potential to disrupt the entire workflow into conflicts (Meier et al, 2013).

\section{Incompatible Goals}

Goals are an important, rather the most fundamental aspect of an organization. For an organization to run as a well-oiled machine it needs hard-working employees who have a proper understanding of their individualistic goals. In an organization, incompatibility in goals may arise due to the different ways of compensation of the managers. A typical example can be considered in the case of a sales manager. A sales manager's income may be related to the number of sales made for the company. This might tempt an individual to provide customers 'freebies', in order to increase delivery and thus sales. On the other hand, the transportation company's income might be linked to the amount of money it can save on various transportation modes. This leads to a conflict between the two bodies and will be at it until the company resolves the issue via some sort of compensation.

\section{Difference in Values}

Sometimes there exists a certain age gap between the employees at the workplace. Although this is mostly a good thing as the junior get a lot of experience and can as well learn from the senior people, but this also leads to certain conflicts between people sharing a generation gap. The values have changed down the time due to the advancement of society, and the society has become more open and accepting too many new reforms, which may not always sit right with the older generation. The difference in values is not always the harbinger of conflicts but the arrogance to of not accepting such change is. Dealing on the lines of such values, quarrels often breakout and insults only fuel such conflicts (Cahn \& Abigail, 2014).

\section{Outcomes of Conflict}

Conflicts, in general, are problematic for the organization as a whole. A few of such negative impacts are mentioned below:

- Mental strain is caused between both the parties involved in the conflict.

- Mutual discontentment is harbored between the two conflicting parties.

- During issues of arguments, feelings of defeat or domination might be felt which would decrease individual morale or in severe cases might lead to feelings of harassment in workplaces.

- A group under constant subordinate conflict might feel threatened.

- Communication breakdown is a common result of conflicts as well.

- Extreme and repetitive case of conflicts might lead to resignation of an employee.

- An atmosphere of mistrust builds up which naturally obstructs proper functioning of the members as a team.

- Productivity is usually lowered a lot, if the conflicts are not resolved (Russ, 2013).

All conflicts are not absolutely detrimental although there are several downsides of organizational conflicts. Some of the noteworthy positive or favorable outcomes are as follows:

- Due to conflicts a broad range of ideas are considered, thus resulting in a better and more universally accepted idea across the organization. 


\section{International Journal of Science and Research (IJSR) \\ ISSN (Online): 2319-7064}

Index Copernicus Value (2016): 79.57 | Impact Factor (2015): 6.391

- Inaccurate assumption on various topics is surfaced.

- There is an overall increase in creativity and participation around the office.

- Individual views that might be sensitive and necessary are acknowledged as well as corrected which in turn help in learning

- Usually after a conflict is resolved the bonding between co-workers increase.

- People come to understand each other better after a conflict thus reducing chances of further conflict.

- In some sort of way, conflicts also release pent up strain (Horton, Bayerl \& Jacobs, 2014).

These conflicts need to be resolved in a proper fashion so as to maintain a balance in the workplace. The proper management of these conflicts constitutes the Conflict Management theory.

\section{Conflict Management Theory}

Conflict management refers to the practice of being able to identify and handle conflicts sensibly, fairly and efficiently. Conflict management may be defined as the opportunity to strengthen relationships and improve situations. Conflicts at workplaces are highly common a subject and most importantly they require attention for their solution. The underlying concept is that both the parties should understand their conflict to be a problem, which needs to be solved mutually so that both parties end up, satisfied. Interpersonal skills help a lot in this area. Proper conveying of the problems that one feels or proper delivery of the arguments one party has instead of randomly throwing opinions at the other party, helps not only to resolve conflicts but also to prevent them in the first place. Self-awareness is highly essential in this arena to let other people understand the viewpoint and motive behind one party's action and thus resolve conflict (Spaho, 2013). The understanding the other person and analyzing their strengths and weaknesses helps a lot in managing organizational conflicts. Assertiveness is the method of expressing thoughts and feelings while asking for what one wants in an appropriate way, thus clearing out confusion and avoiding conflicts to some extent. Five conflict management styles that can be followed effectively to obtain a solution are enlisted below.

\section{Avoidance or Withdrawal}

The individual tries to ignore the conflict passively instead of actually resolving it. He stays neutral in order to avoid the conflict entirely. In case of the Fuji Heavy Industry, the communications regarding the resolving of the issues of payment is done mainly in a more polite manner rather than the aggressive manner that is followed in the other organizations.

\section{Accommodation or smoothing:}

In this style, a more submissive approach is observed. The individual gives in passively to other party in order to resolve the conflict. They 'smoothen' over the differences in mentality to preserve harmony. This method sometimes defines precedence and does not completely involve the participants as one gives in, though this resolves the situation and enhances the ego of the other party (Ellis \&
Abbott, 2012). The CEOs of the companies Apple and Samsung, for example, had organized a meeting with a judge in the U.S. District Court of Northern Carolina in order to attempt a resolution to the high profile patent case that was filed by Apple.

\section{Compromise}

Bargaining is involved in this case, which takes into account the interests of each party so as to create a win-win situation. A give-and-take policy is applied in this style, keeping in mind what is 'acceptable' to each party. Hence, in this case a win-win scenario is created thus satisfying both the parties involved in the conflict. This may lead to everyone feeling like a dead end in some situations though this shows good will and creates friendship (Sudha \& Khan, 2013). In case of the United Auto Workers and the Ford Motor Company, for example, there have been an agreement that they would participate in the integrative style of bargaining. This might help them to bring about a boost in the competitiveness of the automobile industry by putting forward the solutions that may prove to be mutually acceptable for both the organizations.

\section{Competitive or authoritative}

In this case, one of the two parties tries to resolve the conflict via aggressive behavior or by force or authoritative influence. This style usually results in a less satisfied party and a victorious one. The victor usually obtains gains. This style, on a negative view, establishes battleground for the next conflict and gives rise to a series of conflicts. It may also cause in loss or withdrawal of important parties from the organization (Collewaert \& Fassin, 2013).

\section{Collaboration}

This is the most acceptable style of conflict resolving. In this case, the parties jointly try to resolve the problems with the most optimal solution acceptable to all the parties, although this creates an 'everyone wins' scenario this is usually very hard to achieve at all times.

The maintenance or following of the above styles for management of conflicts in organizations usually lead to resolving of the conflict. In addition to these styles, good inter personal skills, self-awareness, empathy, sympathy, confidence, clarity in conversation and other such qualities are required as mentioned above. There is a high chance of resolving that conflict if all these qualities are kept in mind whenever a conflict surfaces (Nielsen \& Einarsen, 2012).

\section{Conclusion}

In lieu of the above discussion, it may be said that organizational conflicts are an inevitable part of any and every organization. There are no such organization that is devoid of conflicts. Organizational conflicts, although undesirable are at times necessary for improvement in a few sectors. There may be various influential factors and causes for organizational conflicts. A noteworthy few of them include communication problems, personality differences, and competition for limited resources. The types of conflicts may vary from individual conflicts to inter-group and intragroup conflicts, from role-based conflicts to ethicaldilemma-centered conflicts. 


\section{International Journal of Science and Research (IJSR) \\ ISSN (Online): 2319-7064}

Index Copernicus Value (2016): 79.57 | Impact Factor (2015): 6.391

These conflicts, as explained earlier, result mostly in negative situations like mistrust among groups, communication breakdown and in extreme cases resignation of employees take place, there are a few positive impacts of conflicts as well, which include better understanding of one another's viewpoints and better bonding once the conflict is resolved. To resolve these conflicts in an organization, conflict management theory can be followed. This theory encircles concepts, which can be followed to avoid conflicts in the first place or resolve conflicts once it has arisen. Proper application of interpersonal skills along with proper implementation of self-awareness concern and clarity in conversation usually helps the conflicts to be resolved. Five main styles of conflict management are usually followed to mitigate organizational conflicts, namely, accommodation, avoidance, competition, compromise and collaboration. Thus, to conclude, organizational conflicts are inevitable and it is to some extent necessary; but severe conflicts should and must be resolved properly, for an organization to grow and flourish.

\section{References}

[1] Abiodun, A. R. (2014). Organizational Conflicts: Causes, Effects and Remedies. International Journal of Academic Research in Economics and Management Sciences, 3(6), 118.

[2] Babatunde, A. (2013). Occupational Stress: A Review on Conceptualisations, Causes and Cure. Economic Insights-Trends \& Challenges, 65(3).

[3] Bhat, A. B., Rangnekar, S., \& Barua, M. K. (2013). Organizational conflict scale: Reexamining the instrument. IUP Journal of Organizational Behavior, 12(1), 7.

[4] Cahn, D. D., \& Abigail, R. A. (2014). Managing conflict through communication. Pearson.

[5] Chen, X. H., Zhao, K., Liu, X., \& Dash Wu, D. (2012). Improving employees' job satisfaction and innovation performance using conflict management. International Journal of Conflict Management, 23(2), 151-172.

[6] Collewaert, V., \& Fassin, Y. (2013). Conflicts between entrepreneurs and investors: the impact of perceived unethical behavior. Small Business Economics, 40(3), 635-649.

[7] de Wit, F. R., Jehn, K. A., \& Scheepers, D. (2013). Task conflict, information processing, and decision-making: The damaging effect of relationship conflict. Organizational Behavior and Human Decision Processes, 122(2), 177-189.

[8] Deyoe, R. H., \& Fox, T. L. (2012). Identifying strategies to minimize workplace conflict due to generational differences. Journal of Behavioral Studies in Business, 5, 1.

[9] Ellis, P., \& Abbott, J. (2012). Strategies for managing conflict within the team. British Journal of Cardiac Nursing, 7(3), 138-140.

[10] Franks, D. M., Davis, R., Bebbington, A. J., Ali, S. H., Kemp, D., \& Scurrah, M. (2014). Conflict translates environmental and social risk into business costs. Proceedings of the National Academy of Sciences, 111(21), 7576-7581.
[11] Gelfand, M. J., Leslie, L. M., Keller, K., \& de Dreu, C. (2012). Conflict cultures in organizations: How leaders shape conflict cultures and their organizational-level consequences. Journal of Applied Psychology, 97(6), 1131.

[12] Graham, S. (2014). Attribution theory: Applications to achievement, mental health, and interpersonal conflict. Psychology Press.

[13] Halevy, N., Cohen, T. R., Chou, E. Y., Katz, J. J., \& Panter, A. T. (2014). Mental models at work: Cognitive causes and consequences of conflict in organizations. Personality and Social Psychology Bulletin, 40(1), 92-110.

[14] Horton, K. E., Bayerl, P. S., \& Jacobs, G. (2014). Identity conflicts at work: An integrative framework. Journal of Organizational Behavior, 35(S1).

[15] Katz, N. H., \& Flynn, L. T. (2013). Understanding conflict management systems and strategies in the workplace: A pilot study. Conflict Resolution Quarterly, 30(4), 393-410.

[16] Katzenbach, J. R., \& Smith, D. K. (2015). The wisdom of teams: Creating the high-performance organization. Harvard Business Review Press.

[17] Kerzner, H. (2013). Project management: a systems approach to planning, scheduling, and controlling. John Wiley \& Sons.

[18] Lumineau, F., Eckerd, S., \& Handley, S. (2015). Interorganizational conflicts: Research overview, challenges, and opportunities. Journal of Strategic Contracting and Negotiation, 1(1), 42-64.

[19] Marion, R., \& Gonzales, L. D. (2013). Leadership in education: Organizational theory for the practitioner. Waveland press.

[20] Meier, L. L., Gross, S., Spector, P. E., \& Semmer, N. K. (2013). Relationship and task conflict at work: Interactive short-term effects on angry mood and somatic complaints. Journal of Occupational Health Psychology, 18(2), 144.

[21] Mikkelsen, E. N., \& Clegg, S. (2017). Conceptions of Conflict in Organizational Conflict Research: Toward Critical Reflexivity. Journal of Management Inquiry, 1056492617716774.

[22] Moore, C. W. (2014). The mediation process: Practical strategies for resolving conflict. John Wiley \& Sons.

[23]Nain, A. S. M. (2017). Conflict perspectives in analyzing and understanding organizational behavior. Jurnal Kemanusiaan, 2(2).

[24] Nielsen, M. B., \& Einarsen, S. (2012). Outcomes of exposure to workplace bullying: A meta-analytic review. Work \& Stress, 26(4), 309-332.

[25] Odle-Dusseau, H. N., Britt, T. W., \& GreeneShortridge, T. M. (2012). Organizational work-family resources as predictors of job performance and attitudes: The process of work-family conflict and enrichment. Journal of occupational health psychology, 17(1), 28.

[26] Prause, D., \& Mujtaba, B. G. (2015). Conflict management practices for diverse workplaces. Journal of Business Studies Quarterly, 6(3), 13.

[27] Riaz, M. K., \& Junaid, F. A. (2012). Types, sources, costs \& consequences of workplace conflict. 


\section{International Journal of Science and Research (IJSR) \\ ISSN (Online): 2319-7064}

Index Copernicus Value (2016): 79.57 | Impact Factor (2015): 6.391

[28] Russ, T. L. (2013). The relationship between Theory $\mathrm{X} / \mathrm{Y}$ : assumptions and communication apprehension. Leadership \& Organization Development Journal, 34(3), 238-249.

[29] Siira, K. (2012). Conceptualizing managerial influence in organizational conflict-a qualitative examination. Negotiation and Conflict Management Research, 5(2), 182-209.

[30] Sonnentag, S., Unger, D., \& Nägel, I. J. (2013). Workplace conflict and employee well-being: The moderating role of detachment from work during offjob time. International Journal of Conflict Management, 24(2), 166-183.

[31] Spaho, K. (2013). Organizational communication and conflict management. Management: journal of contemporary management issues, 18(1), 103-118.

[32] Sudha, K. S., \& Khan, W. (2013). Personality and motivational traits as correlates of workplace deviance among public and private sector employees. Journal of Psychology, 4(1), 25-32.

Volume 6 Issue 12, December 2017

www.ijsr.net 